\title{
Образное мышление и его развитие на уроках географии
}

\author{
Т. М. Позднякова $\bowtie$, В. П. Макаренко \\ Приамурский государственный университет им. Шолом-Алейхема, Российская Федерация \\ (679016, г. Биробиджан, ул. Ленина, 40)
}

\begin{abstract}
Аннотация: Цель данной статьи заключается в рассмотрении образного мышления как одного из важнейших психических процессов и компонентов успешного обучения, а также раскрытии некоторых возможностей его развития на уроках географии. В процессе проведения исследования, положенного в ее основу, использовались следующие методы: аналитический, синтетический, экспериментальный. Результаты: раскрыто значение сформированности образного мышления для успешного включения школьников в образовательный процесс. Обозначены некоторые методические аспекты развития образного мышления в процессе учебной деятельности. Представлены и проанализированы результаты педагогического эксперимента по развитию образного мышления на уроках географии. $B b l$ водbl: Образное мышление является неотъемлемой частью общей культуры человека и географической культуры - в частности. Содержание географии как учебного предмета имеет широкие возможности для развития образного мышления. Внедрение в образовательный процесс приемов, направленных на развитие образного мышления, способствует преодолению «эмоциональной лености» школьников как следствия клипового мышления и способствуют переходу познавательной деятельности от представлений к понятиям, от чувственного уровня познания - к рациональному. В данной связи, развитие образного мышления представляет собой важную ступень, обеспечивающую как становление логического мышления, так и формирование мышления комплексного. Применение методов развития образного мышления на уроках географии повышает не только уровень его сформированности, но и способствует росту интереса к географии как учебному предмету. Это свидетельствует об эффективности материалов, которые были разработаны педагогом и применены в процессе проведения педагогического эксперимента.
\end{abstract}

Ключевые слова: образное мышление, клиповое мышление, методика обучения географии, географическая культура, педагогический эксперимент.

Для цитирования: Позднякова Т. М., Макаренко В. П. Образное мышление и его развитие на уроках географии // Вестник Воронежского государственного университета. Серия География. Геоэкология, 2020, № 3, c. 86-93. DOI: https://doi.org/10.17308/geo.2020.3/3028

\section{ВВЕДЕНИЕ}

На современном этапе общественного развития, требующем формирования так называемого человеческого капитала, перед системой образования стоит ряд задач. Основные из них тесно связаны с развитием мыслительной деятельности учащихся как основы деятельности познавательной, следовательно - учебной, научной и профессиональной. В данной связи, актуальными становятся исследования, направленные на изучение разных сторон мышления.

() Позднякова Т.М., Макаренко В.П., 2020

П Позднякова Татьяна Михайловна, e-mail: russland-54@mail.ru (c) (i) Контент доступен под лицензией Creative Commons Attribution 4.0 License.
Система образования, сложившаяся в нашей стране, направлена преимущественно на развитие логического мышления учащихся. При этом часто оно противопоставляется мышлению образному, которому отводится второстепенная роль в учебном процессе. Однако современные тенденции в модернизации российского образования в качестве приоритета выдвигают формирование у школьника определенной совокупности личностных качеств, необходимых ему для успешной социализации и саморазвития. На первый план в данной связи выходит не усвоение всего объема знаний, а 
развитие духовной сферы человека. Это весьма сложно при недостаточном уровне сформированности образного мышления, которое является неотъемлемой составляющей творческой личности.

Поскольку наиболее популярные в образовательной практике учебно-методические материалы, методы и примы обучения сохраняют преимущественно логическую направленность, недостаточный уровень сформированности образной составляющей мышления у учащихся к настоящему времени становится очевидным.

Роль образного мышления как неотъемлемого условия эстетического развития, интеллектуализации личности вследствие высокой степени развития эмоциональности и воображения изучали Н. Л. Коломинский, Р. Н. Немов, Н. Л. Тихомиров, Г. И. Шатковский. Проблемы развития мышления представителей разных возрастных групп исследовали многие отечественные и зарубежные ученые: Л.С. Выготский, Л.А. Венгер, Р. С. Немов, Л. С. Рубинштейн, Ж. Пиаже и другие [4-8,]. В работах Б. Г. Ананьева, Т. В. Галкиной, Л. Л. Гурова, А. А. Люблинской и других исследователей показано значение развитости образного мышления в выполнении разнообразных операций с целью совершения каких-либо видов деятельности, раскрывают специфику особенности его функционирования $[1,3,9,10]$.

Исследование Г. И. Минской показало, что усвоение форм образного познания, которое начинает развиваться у ребенка еще в дошкольном возрасте и продолжается в течение младшего и среднего школьного возраста, формирует первичную картину мира и подготавливает почву для развития логического мышления в будущем [11]. Недостаточное внимание к развитию образной составляющей мышления часто снижает познавательный интерес к учебному предмету. Особенно это заметно при изучении дисциплин естественнонаучного цикла, тесно связанных с необходимостью умения оперировать отвлеченными объектами, в том числе - географии. В свою очередь, именно в них содержится мощный потенциал для формирования образов. В данной связи, проведенный нами педагогический эксперимент по развитию образного мышления на уроках географии представляется весьма актуальным и имеет практическую значимость.

\section{МЕТОДИКА ЭКСПЕРИМЕНТА}

Цель проведенного эксперимента заключалась в выявлении эффективности внедрения приемов, направленных на развитие образного мышления, в образовательный процесс.

Для достижения данной цели нами были поставлены следующие задачи: 1) выявить роль развития образного мышления в процессе формирования географической и общей культуры человека; 2) провести отбор способов развития образного мышления в рамках уроков географии; 3) подготовить и провести апробацию системы заданий, направленных на развитие образного мышления при изучении курса «География России» и провести анализ эффективности ее применения.

В качестве экспериментальной базы были выбраны учащиеся 8 класса одной из общеобразовательных школ Еврейской автономной области.

Рабочая гипотеза данного эксперимента заключалась в том, что применение заданий, направленных на развитие образного мышления у школьников, повысит уровень данного показателя и интерес к изучению географии.

Теоретической основой эксперимента являются следующие постулаты. Мышление - основа познания [7]. Человеком в ходе познавательной деятельности выполняется два взаимосвязанных процесса: а) чувственно-сенсорное познание, на уровне которого происходит появление образов и совершаются определенные операции с ними; б) рациональное познание, когда формируются и развиваются абстрактные мысли [11].

При этом мысль, по мнению Л.С. Выготского, появляется в чувственно-волевой сфере человека $[7,8]$. Чувственное познание состоит из трех основных типов наглядных образов: ощущений, восприятий и представлений.

Ощущение отражает отдельное свойство объекта, которое возникает при воздействии данного объекта на органы чувств. Целостное отражение объектов под влиянием чувств формируется посредством восприятия, которое, в свою очередь, есть результат умственной деятельности, синтезирующей разнообразные ощущения в одно целое, и имеющей осмысленный характер.

Представления как визуализируемые образы каких-либо объектов формируются на основе предшествующих восприятий [11]. Возникающее в сознании представление часто влечет за собой появление цепочки других представлений. Так формируются взаимосвязанные комбинации образов - ассоциаций. В процессе мышления содержание информации постоянно перерабатывается.

Рациональное познание осуществляется в ходе логического (дискурсивного) мышления, когда 
человек мысленно перемещается за пределы чувственного познания. Важнейшими формами логического мышления являются понятия, суждения, умозаключения.

Понятием называют мысль о предмете, выделяющую его существенные характеристики. Оно является главной составляющей логической стороны мышления. Человек употребляет понятия в мыслительном процессе в составе сформулированных суждений - утверждающих или отрицающих что-либо мыслей об объекте [11].

Суждения бывают двух типов. Первые выражают знания, полученные в процессе непосредственного наблюдения за действительностью, вторые же создаются посредством умозаключений логических рассуждений, основанных не только на конкретных знаниях о некоторых существующих объектах, которые дает нам чувственное познание. Большое значение при их формулировании приобретает имеющийся опыт, знания, способность их обобщать и делать выводы, в результате которых человек должен предвидеть результаты и устанавливать взаимосвязи явлений, событий или поступков.

В образном мышлении используются образы, непосредственно извлекаемые из памяти или воссоздаваемые воображением. Оно является как бы связующим звеном познания чувственного и рационального. Без сформированности определенного спектра комбинаций образов на уровне представлений развитие логического мышления как совокупности понятий, а затем и последующих за ними единиц, представляется весьма затруднительным.

Изучение особенностей мыслительного развития в масштабных психодиагностических исследованиях, которые многократно проводились под руководством Д. Б. Эльконина, показывает более высокие результаты обучения у испытуемых с достаточно высокими показателями развития образного мышления, их интеллектуализация проходит более эффективно. Дети с недостаточно сформированным изучаемым показателем часто характеризуются формальным отношением к процессу обучения, у них существенно осложнен процесс формирования логической стороны мышления [11].

В 1940-х годах Ж. Пиаже были обоснованы общие закономерности в функционировании восприятия. Он также выделил основные этапы, которые последовательно проходит процесс усвоения информации: 1) моторно-сенсорный, на котором человек получает информацию посредством органов чувств; 2) образный (символьный), когда на этой основе формируются какие-либо образы; 3) логический, связанный с пониманием образно представляемой информации; 4) лингвистический, где происходит вербализация воспринятой и осмысленной информации [11].

Мышление как целостный процесс обеспечивается последовательным прохождением данных этапов. Нарушение их последовательности часто является причиной снижения эффективности мышления, недопонимания предъявляемой информации. Если учащимся предлагают выполнять задания, на третьем уровне мышления без должного внимания первому и второму этапам, часто возникают проблемы с успеваемостью, снижается интерес к обучению.

Сензитивным для развития образного мышления является дошкольный и младший школьный возраст, но в разной степени активности этот процесс протекает постоянно. Поэтому при осуществлении образовательного процесса важным является как диагностика актуального уровня развития образного мышления школьников, так и применение разнообразных методик, направленных на его активизацию.

География является тем учебным предметом, который предполагает работу как с реальными объектами, так и с широким применением всевозможных образов. Кроме того, многие географические объекты и явления обозначаются в символизированном виде, что делает необходимым активизацию особых мыслительных механизмов. Они способствуют более полноценному усвоению содержания учебного материала в ходе предшествующей работы с географическими образами, представляющими собой определенную форму отражения окружающего мира в сознании человека. Географические представления, наряду с другими элементами (понятиями, терминами и фактами) В. П. Максаковский относит к языку географии [12]. Овладение им является необходимым условием становления культуры географической как одного из слагаемых личностной культуры.

Географические образы тесно связаны с художественными описаниями, вызывающими устойчивый познавательный интерес, что способствует более глубокому пониманию изучаемых природных и социально-экономических объектов и явлений. В данной связи, преподавание школьной географии должно опираться на формирование образно насыщенной картины мира.

Образное мышление формируется посредством определенных методов и приемов обучения. 
Примеры заданий, направленных на развитие образного мышления в курсе «География России», 8 класс [Table 1. Examples of tasks aimed at developing imaginative thinking in the course "Geography of Russia", grade 8]

\begin{tabular}{|c|c|c|}
\hline $\begin{array}{c}\text { № } \\
\text { П/П }\end{array}$ & $\begin{array}{l}\text { Тематический раздел/ } \\
\text { Thematic section }\end{array}$ & Примеры заданий/ Examples of tasks \\
\hline 1 & $\begin{array}{l}\text { Рельеф России. Полезные } \\
\text { ископаемые }\end{array}$ & $\begin{array}{l}\text { Послушайте рассказ учителя о вершинах России } \\
\text { (Эльбрус, Народная, Белуха, Ключевская Сопка). } \\
\text { Нарисуйте «портрет» одной из них. Выделите общие } \\
\text { и единичные признаки, характерные для горных } \\
\text { вершин. }\end{array}$ \\
\hline 2 & $\begin{array}{l}\text { Климат России. Влияние } \\
\text { климата на жизнь } \\
\text { человека }\end{array}$ & $\begin{array}{l}\text { Представьте, что вы живете в (каком-либо) } \\
\text { климатическом поясе. Опишите: } \\
\text { - как выглядит ваше жилище; } \\
\text { - какую одежду вы носите; } \\
\text { - чем вы питаетесь; } \\
\text { - как устроен ваш быт; } \\
\text { - ваши ежедневные занятия. } \\
\text { Сопоставьте ваш рассказ с рассказами } \\
\text { одноклассников, обоснуйте черты их сходства и } \\
\text { различия. }\end{array}$ \\
\hline 3 & Россия - морская держава & $\begin{array}{l}\text { Вы плывете по морям России на теплоходе, } \\
\text { мелькают названия портов: Калининград, } \\
\text { Архангельск, Мурманск, Диксон, Владивосток, } \\
\text { Новороссийск, Астрахань, Санкт-Петербург. В каких } \\
\text { вы побывали морях? Какое из них вам понравилось } \\
\text { больше и почему? }\end{array}$ \\
\hline 4 & Внутренние воды России & $\begin{array}{l}\text { Вспомните стихотворение М. Лермонтова «Терек». } \\
\text { Проанализируйте гидрологические особенности } \\
\text { этого водотока, сравните с другими известными вам } \\
\text { реками. }\end{array}$ \\
\hline 5 & Почвы России & $\begin{array}{l}\text { Составьте рассказ-описание о том, как образуется } \\
\text { почва от имени представителя одного из царств } \\
\text { природы (растения, животного и т.п.). В чем } \\
\text { заключается ваша роль в процесе } \\
\text { почвообразования? }\end{array}$ \\
\hline 6 & Природные зоны России & $\begin{array}{l}\text { Представьте, что вы оказались в тайге. Что вы } \\
\text { видите вокруг себя? Что слышите? Что ощущаете? } \\
\text { Мысленно переместитесь в степь. Что теперь вы } \\
\text { чувствуете? Объясните, чем отличается тайга от } \\
\text { степи. }\end{array}$ \\
\hline
\end{tabular}

Их выбор зависит от возрастно-психологических особенностей целевой группы. Так, для младших школьников могут применяться следующие виды деятельности: эмоциональное чтение, игры с перевоплощениями; рисование с допридумыванием; сочинение или фантазирование; отгадывание загадок и т.п. В подростковом возрасте целесообразно эти методики расширять, углублять и дополнять с учетом уже сформированных у учащихся знаний и представлений.

При выборе способов развития образного мышления у современных школьников, как пред- ставляется, необходимо учитывать такую особенность, как его формальная схожесть с мышлением клиповым - ведь в обоих случаях мы имеем дело с образом.

Под клиповым мышлением понимают совокупность операций короткими, часто не связанными по смыслу, фрагментами, в результате чего человек оказывается не способным осмысливать более объемную, однородную и последовательную информацию. Его базовой характеристикой является предъявление информации без наличия контекста, что не способствует формированию комплек- 
Количественные результаты педагогического эксперимента по развитию образного мышления на уроках географии (в \% от общего числа испытуемых)

[Table 2. Quantitative results of the pedagogical experiment on the development of imaginative thinking in geography lessons (in \% of the total number)]

\begin{tabular}{|l|c|c|}
\hline \multirow{2}{*}{$\begin{array}{c}\text { Качественный показатель / } \\
\text { Qualitative indicator }\end{array}$} & \multicolumn{2}{|c|}{ Этап эксперимента / Experiment phase } \\
\cline { 2 - 3 } & констатирующий / stating & итоговый / final \\
\hline \multicolumn{3}{|c|}{ Познавательный интерес } \\
\hline ситуативный & 70 & 30 \\
\hline учение по необходимости & 20 & 40 \\
\hline повышенный & 10 & 30 \\
\hline \multicolumn{2}{|c|}{ Уровень развития образного мышления } \\
\hline очень низкий & 10 & 0 \\
\hline низкий & 50 & 20 \\
\hline средний & 30 & 50 \\
\hline высокий & 10 & 20 \\
\hline очень высокий & 0 & 10 \\
\hline
\end{tabular}

сной картины мира [13]. Отмечено, что, наряду с некоторыми плюсами (такими как защита от чрезмерных информационных перегрузок), оно имеет очевидные минусы: формирование шаблонности, стереотипности мышления, снижение воображения и желания думать, сложность восприятия и осмысленного понимания информации без визуального и анимационного сопровождения, и т.д. [14].

При развитии образного мышления, в отличие от клипового, где нам предлагается картинка в готовом виде, представления «рождаются» в сфере чувственного познания, следовательно, их формирование предвосхищается начальными ступенями познавательной деятельности - ощущениями и восприятием. Такой образ будет подготавливать учащегося к формированию понятий, суждений, умозаключений.

Вместе с тем, хорошо развитое клиповое мышление современного школьника, в силу наличия у него разнообразного «набора» картинок-образов, может способствовать развитию мышления образного. Как представляется, оптимальным приемом обучения географии, направленным на развитие образного мышления с опорой на положительные стороны клипового мышления, может являться, к примеру, визуализация географических образов посредством литературных произведений.

Далее приведен фрагмент планирования разделов курса географии с примерами заданий, направленных на развитие образного мышления учащихся при изучении раздела «Природа России» (таблица 1).

Непосредственно педагогический эксперимент состоял из трех этапов.
На констатирующем этапе проводилось определение у участников эксперимента актуального уровня развития образного мышления. Для этого были применены следующие методики: тест «Твой интерес» и упражнение «Нелепицы». Цель теста «Твой интерес»- определить интерес учащихся к урокам географии. Посредством заданий второго упражнения оцениваются первичные представления ребенка об окружающей действительности, а также умения устанавливать причинно-следственные связи объектов, явлений, поступков, то есть вербализировать собственные мысли $[2,6]$.

На формирующем этапе педагогического эксперимента в течение учебного семестра на уроках географии широко применялся комплекс заданий, развивающих способность воссоздавать мыслительные образы. На третьем, итоговом этапе, проводилось повторное анкетирование и оценка уровня развития образного мышления участников эксперимента.

\section{ОБСУЖДЕНИЕ РЕЗУЛЬТАТОВ}

Результаты констатирующего и итогового экспериментов представлены в таблице 2 .

Анализ результатов педагогического эксперимента выявил повышение уровня развития образного мышления у его участников. Если на констатирующем этапе $50 \%$ испытуемых имел низкий уровень развития оцениваемой характеристики, то на итоговом доминантным становится средний качественный показатель. Кроме того, отмечен прирост доли учащихся с высоким и очень высоким уровнем развития образного мышления. Положительная динамика наблюдается также в от- 
ношении формирования познавательного интереса к географии. Таким образом, рабочая гипотеза эксперимента была подтверждена.

\section{ЗАКЛЮЧЕНИЕ}

Образное мышление является необходимой частью общей культуры человека. География как учебный предмет имеет широкие возможности для формирования образного мышления. Таким образом, различные аспекты развития образного мышления школьников на уроках географии вызывают большой теоретический и практический интерес.

Внедрение в образовательный процесс приемов, направленных на развитие образного мышления, способствуют преодолению «эмоциональной лености» как следствия клипового мышления и способствуют переходу познавательной деятельности от представлений к понятиям, от чувственного уровня - к рациональному. Педагогический эксперимент, направленный на развитие образного мышления на уроках географии, выявляет положительную динамику как уровня развития данной характеристики, так и повышение интереса к учебному предмету, что свидетельствует об эффективности применяемых материалов.

\section{СПИСОК ЛИТЕРАТУРЫ}

1. Ананьев Б. Г. Человек как предмет познания. Ленинград, ЛГУ, 1968. 399 с.

2. Анастази А., Урбина С. Психологическое тестирование. СПб., Питер, 1997. 689 с.
3. Андреев В. И. Диалектика воспитания и самовоспитания творческой личности. Казань, КГУ, 2008. 226 с.

4. Битянова М. Р. Школьный психолог: идея психолого- педагогического сопровождения // Директор школьbl, 1997, № 3, с. 4-12.

5. Божович Л.И. Личность и ее формирование в детском возрасте. СПб., Питер, 2008. 400 с.

6. Венгер А. Л. Психологические рисуночные тесmbl. М., ВЛАДОС-ПРЕСС, 2003. 160 с.

7. Выготский Л. С. Педагогическая психология. М., Педагогика, 1991. 480 с.

8. Выготский Л.С. Воображение и творчество 8 детском возрасте. М., Педагогика, 2001. 360 с.

9. Галкина Т. В., Алексеева Л. Г. Диагностика и развитие креативности. М., Наука, 1991. С. 170-178.

10. Ильин Е. П. Психология творчества, креативности, одаренности. СПб., Питер, 2009. 434 с.

11. Исследование мышления в советской психологии. М., Директ-Медиа, 2008. 914 с.

12. Максаковский В.П. Географическая картина мира. М., ВЛАДОС, 1998. 416 с.

13. Саблина А. А. Возможность формирования системного мышления при развитом клиповом у современных школьников // Форум молодых ученых, 2019, № 8(36), с. 278-282.

14. Смирнова А.А. Клиповое мышление учащихся: за и против // Новшества в области педагогики и психологии. Сборник научных трудов по итогам международной научно-практической конференции. Тюмень, ТГУ, 2016, с. 76-77.

Конфликт интересов: Авторы декларируют отсутствие явных и потенциальных конфликтов интересов, связанных с публикацией настоящей статьи.

Поступила в редакцию 27.03.2020

Принята к публикации 26.07.2020

\title{
The Imaginative Thinking and its Development in Geography Lessons
}

\author{
T. M. Pozdnyakova ${ }^{凶}$, V.P. Makarenko \\ Sholom-Aleichem Priamursky State University, Russian Federation \\ (40, Lenina st., Birobidzhan, 679016)
}

Abstract: The purpose of this article is to consider figurative thinking as one of the most important mental processes and components of successful learning, as well as to reveal some of the possibilities for its develop-

(C) Pozdnyakova T.M., Makarenko V.P., 2020

\Tat'yana M. Pozdnyakova, e-mail: russland-54@mail.ru

(c) (i) The content is available under Creative Commons Attribution 4.0 License.

Вестник ВГУ, Серия: География. Геоэкология, 2020, № 3, 86-93 


\section{T.M. Pozdnyakova, V.P. Makarenko}

ment in geography lessons. In the process of conducting the research, which was the basis for it, the following methods were used: analytical, synthetic, experimental. Results: The significance of the formation of imaginative thinking for the successful inclusion of schoolchildren in the educational process is revealed. Some methodological aspects of the development of figurative thinking in the process of educational activity are indicated. The results of a pedagogical experiment on the development of figurative thinking in geography lessons are presented and analyzed. Conclusions: Imaginative thinking is an integral part of the general culture of a person and geographic culture - in particular. The content of geography as an academic subject has ample opportunities for the development of figurative thinking. The introduction of techniques aimed at the development of figurative thinking into the educational process helps to overcome the "emotional laziness" of schoolchildren as a consequence of clip thinking and contributes to the transition of cognitive activity from ideas to concepts, from the sensory level of cognition to rational. In this regard, the development of figurative thinking is an important step, providing both the formation of logical thinking and the formation of complex thinking. The use of methods for the development of figurative thinking in geography lessons increases not only the level of its formation, but also contributes to the growth of interest in geography as an academic subject. This testifies to the effectiveness of the materials that were developed by the teacher and applied in the process of conducting the pedagogical experiment.

Key words: imaginative thinking, clip thinking, methods of teaching geography, geographical culture, pedagogical experiment.

For citation: Pozdnyakova T.M., Makarenko V.P. The imaginative thinking and its development in geography lessons. Vestnik Voronezskogo gosudarstvennogo universiteta. Geografia geoekologia, 2020, No. 3, pp. 86-93. (In Russ.) DOI: https://doi.org/10.17308/geo.2020.3/3028

\section{REFERENCES}

1. Anan'ev B. G. Chelovek kak predmet poznaniya [Man as an object of knowledge]. Leningrad, Publ. LGU, 1968. 339 p. (In Russ.)

2. Anastazi A., Urbina S. Psixologicheskoe testirovanie [Psychological testing]. St. Petersburg, Publ. Piter, 1997. 689 p. (In Russ.)

3. Andreev V.I. Dialektika vospitaniya i samovospitaniya tvorcheskoy lichnosti [Dialectics of education and self-education of a creative person]. Kazan', Publ. KGU, 2008. 226 p. (In Russ.)

4. Bityanova M. R. Shkol'nyj psixolog: ideya psixologo-pedagogicheskogo soprovozhdeniya [School psychologist: the idea of psychological and pedagogical support]. Direktor shkoly, 1997, no. 3, pp. 4-12. (In Russ.)

5. Bozhovich L. I. Lichnost'i ee formirovanie v detskom vozraste [Personality and its formation in childhood]. St. Petersburg, Publ. Piter, 2008. 400 p. (In Russ.)

6. Galkina T. V., Alekseeva L. G. Diagnostika i razvitie kreativnosti [Diagnostics and development of creativity]. Moscow, Publ. Nauka, 1991, pp. 170-178. (In Russ.)

7. Il'in E.P. Psixologiya tvorchestva, kreativnosti, odarennosti [Psychology of creativity, creativity, and giftedness]. St. Petersburg, Publ. Piter, 2009. 434 p. (In Russ.)

8. Issledovanie myshleniya v sovetskoy psixologii $[\mathrm{Re}-$ search of thinking in Soviet psychology]. Moscow, Publ. Direkt-Media, 2008. 914 p. (In Russ.)
9. Maksakovskij V.P. Geographicheskaya kartina mira [Geographical picture of the world]. Moscow, Publ. Vlados, 1998. 416 p. (In Russ.)

10. Sablina A. A. Vozmozhnost' formirovaniya sistemnogo myshleniya pri razvitom klipovom myshlenii u sovremennyh shkol'nikov [The possibility of formation of system thinking in the developed klipovoy thinking among modern students]. Forum molodyh uchenyh, 2019, no. 8(36), pp. 278-282. (In Russ.)

11. Smirnova A. A. [Clip thinking of students: pros and cons]. Sbornik nauchnyh trudov po itogam mezhdunarodnoj nauchno-practicheskoj konferencii [Collection of scientific papers on the results of the international sci. and pract. conf.]. Tyumen', Publ. TGU, 2016, pp. 76-77. (In Russ.)

12. Venger A.L. Psixologicheskie risunochnye testy [Psychological drawing tests]. Moscow, Publ. Vlados-Press, 2003. 160 p. (In Russ.)

13. Vygotskij L.S. Pedagogicheskaya psixologiya [Educational psychology]. Moscow, Publ. Pedagogika, 1991. 480 p. (In Russ.)

14. Vygotskij L.S. Voobrazhenie i tvorchestvo $v$ detskom vozraste [Imagination and creativity in childhood]. Moscow, Publ. Pedagogika, 2001. 360 p. (In Russ.)

Conflict of interests: The authors declare no information of obvious and potential conflicts of interest related to the publication of this article.

Received: 27.03.2020 Accepted: 26.07.2020 
Позднякова Татьяна Михайловна

кандидат географических наук, доцент Приамурского государственного университета им. Шолом-Алейхема, г. Биробиджан, Российская Федерация, ORCID: http://orcid.org/0000-0002-9292-8142, e-mail: russland-54@mail.ru

Макаренко Вера Прокопьевна

кандидат биологических наук, доцент Приамурского государственного университета им. Шолом-Алейхема, г. Биробиджан, Российская Федерация, ORCID: http://orcid.org/0000-0002-9293-8153, e-mail: russland-54@mail.ru
Tat'yana M. Pozdnyakova

Cand. Sci. (Geogr.), Assoc. Prof. of the Priamursky State University named after Sholom-Aleichem, Birobidzhan, Russian Federation, ORCID: http://orcid.org/0000-0002-9292-8142, e-mail: russland-54@ mail.ru

Vera P. Makarenko

Cand. Sci. (Biol.), Assoc. Prof. of the Priamursky State University named after Sholom-Aleichem, Birobidzhan, Russian Federation, ORCID: http://orcid.org/0000-0002-9293-8153, e-mail: russland-54@mail.ru 